\title{
The Aims of the University of Occupational and Environmental Health, Japan
}

- Opening Address as the First President of the University -

Kenzaburo Tsuchiya, President

1. The university will educate physicians to educate themselves and to have as their lifelong philosophy a devotion to serving the health needs of humanity.

2. By focusing attention on the occupational and general environment of man, the university will endeavor to develop and integrate the field of environmental science with life science.

3. The university will strive to develop a new discipline of ecology which incorporates economic factors.

4. The university will not only firmly establish occupational medicine in an industrialized and postindustrialized society, but will also integrate it with comprehensive community health services.

The university, as a pioneer in the field of the medical and health sciences in the 21st century, will strive to accomplish all these goals for the purpose of establishing a new society and a better life for all. This we hold to be our mission and the reason for the foundation of the University of Occupational and Environmental Health, Japan.

To the very first students of the University of Occupational and Environmental Health, congratulations on your entrance to this new university. I hope all of you will successfully complete your six years of medical study, keeping ever in mind the excitement of this memorable day.

You must all have been diligent in your studies for the entrance examination. However, the strenuous effort that you have made is nothing compared to the study, and more important, the self-discipline and training which is required to become a good physician. Have you ever seriously thought about exactly what a medical doctor is, and what the mission of a doctor is? Up until now you have probably not had the time to give much thought to exactly what the University of Occupational and Environmental Health is, or to what the relationship is between occupational and community medicine. Therefore, I would like to speak to you briefly on this memorable day about the spirit in which the university has been founded and the direction it hopes to take. 


\section{On Becoming a "Doctor of Excellence" (Jōi)}

I believe medicine to be a vocation in which one serves with an unceasing love of humanity. Thus it is not enough to simply study and master technical skills. One must pursue the study of philosophy throughout life, always asking what is life and what is death. Good doctors are those who give medical treatment based on a philosophy of life. There is a term, $j \bar{o} i$, which has existed since ancient times in Japan. This term may be loosely translated as a "doctor of excellence." Such a doctor devotes himself not only to healing disease but also to preventing disease by seeking its cause, and furthermore, to maintaining and improving good health. I will expect you to make constant efforts to become a "doctor of excellence," with a serious philosophy of life ever-present in your mind.

\section{On Developing and Integrating Environmental Science with Life Science}

We must ask ourselves what factors cause us to be sick or healthy. Sickness and health are the results of an interaction between heredity and environment. Heredity is very complex because it is determined by the genes inherited from one's parents. Environment, which means man's total environment from the time before birth to the time of death, is also very complex. It includes such chemical, physical, and biological elements as water, air, and food in addition to countless other factors such as socioeconomics, psycology, and medicine. Since sickness and health are determined by the involvement of such complex hereditary and environmental elements, it is natural that we have so many difficulties in elucidating their causes. Modern medicine, in challenging these difficulties, is clarifying the causes little by little, and has succeeded to some degree in treating and preventing disease. It has also contributed to a decrease in mortality and to the prolongation of human life.

However, the extremely rapid development of modern industry is destroying man's environment to such an extent that the question of the destruction of mankind itself is being raised. Furthermore, the science of physics, which should be the most promising of the modern sciences, has come to regard itself with suspicion and has begun to reflect upon itself. As a result of this reflection, the field of life sciences was born for the purpose of turning physics to the use of mankind and to seek the answer to the age-old question, "what is life?".

Environmental science has been developed to stop industrialization from destroying the environment and to make industry work for rather than against human life. Life science and environmental science have only just begun, and in this sense, they can be said to be sciences of the 21 st century.

We can consider environmental science as having developed from traditional ecology. Ecology in its origin was the study of the relationship between living creatures and their environments. However, until recently, the factor of human activity within the bounds of ecology was not taken into serious consideration. It is here that the 
University of Occupational and Environmental Health must make pioneering efforts in medicine in the 21st century and, focusing special attention on the occupational environment, attempt to integrate environmental science with life science and develop them together accordingly.

\section{On Developing a New Ecology}

Medicine in the 21st century must also work together with the economy. By this I mean not simply what is termed "medical economics," but an organic union between medicine and economics. Unless this union is achieved, the medical sciences will not be able to develop as they should. Economic support for the progress of medicine and medical services is essential. However, such progress will not result automatically simply because a nation or a community is wealthy. In other words, medicine is not a mere variable of monetary wealth or GNP, but rather an integral part of a nation's economy, and must be recognized as such.

The words "economy" and "ecology" stem from the same Greek word eco, meaning "house." Thus they are similar in origin, yet have developed in separate directions as though they had nothing in common. I would like to emphasize here that environmental science + life science $=$ ecology, and economics is naturally involved in the system of human environment.

Thus the University of Occupational and Environmental Health must also focus on economics in its endeavors to develop a new ecology.

\section{On Working for the Organic Integration of Occupational Medicine and Community Medical Services}

Occupational medicine in Europe, America, Japan and other nations throughout the world has developed as a result of the industrial revolution in England. There exist, however, certain differences in the subject matter studied and practiced in each country. In Japan it was not until after World War II that the practice of occupational medicine, or occupational health, was established with the enactment of the Labor Standards Law and with it came a number of problems in the study and practice of occupational meidicine. The source of the problems was that in the rapidly changing and industrializing society, there were no reactions formed on the part of environmental science or ecology in the new, as opposed to the traditional, sense of the word of ecology. That is to say, we must honestly face the fact that the establishment and practice of basic medical concepts have not kept pace with the changes in the social, economic, physical, chemical, and psychological environments.

The same can be said of community health services. The Japanese Medical Association has for a long time been working at introducing a concept of comprehensive community health care which incorporates both prevention and public health in community medicine, but this idea has not yet been fully understood or adopted by the society at large. Occupational medicine, focusing attention on prevention, provides 
medical care for industrial population while community medicine, including geriatric care, emphasizes treatment. Of course, improvement of general health as well as rehabilitation are involved in both occupational and community health.

This University of Occupational and Environmental Health has been established to fill the need for more physicians specializing in occupational health in a changing society. However, as I have clearly emphasized before, it is not enough for specialists in occupational health to be skilled only in the technical aspects of the field. With this in mind, the University of Occupational and Environmental Health is currently drawing up plans not only to further establish occupational health in an industrialized society, but to provide an example here in the community of Kitakyushu of occupational health working hand in hand with community medical services to form an integrated organic entity.

\section{On Establishing a New Type of Social Welfare}

Much is expected of medicine now and in the future. These expectations include not only the purely medical demands of disease prevention, treatment, and rehabilitation, but also include social and psychological demands for a life well worth living. Among these demands will be included those which are not absolutely necessary as well as selfish demands which cannot be accepted by society. Thus these expectations produce an extremely complex problem which cannot be solved by medicine alone. I am convinced that the key to solving the problem is in establishing a new type of social welfare and ethics through which mankind can achieve a more meaningful existence.

The University of Occupational and Environmental Health must make every effort to respond not only to changes in the physical, social, and economic environments but also to changing social values and must seriously examine the role of medicine in a society with a new type of social welfare in which man must be able to enjoy a better quality of life.

\section{Conclusion}

I am honored to be the first president of the University of Occupational and Environmental Health and have, at this first entrance ceremony of the medical school, spoken on the spirit in which this university has been founded and on the goals it hopes to achieve. The eyes of society are watching to see how well you learn and what kind of physicians you will become. It is up to you to live up to the founding spirit about which I have spoken. In the future you will work not only in Japan but will disperse throughout the world, and I have great hopes that you will dedicate yourselves to working for the health and welfare of the Japanese people and of all the peoples of the world. I firmly believe that you will on this memorable day vow to work very hard to fulfill this mission. 